\title{
GEOSEA - ITS ORIGIN AND DEVELOPMENT
}

by

\section{B.K. Tan and T.T. Khoo}

The fourth Regional Conference on the Geology, Mineral and Energy Resources of Southeast Asia - GEOSEA IV - held in Manila, Philippines, in November 1981, was a milestone in the development of regional cooperation in the geosciences in Southeast Asia. It was the first time that this non-governmental conference was held in the Philippines, and it provided a rare opportunity for representatives of Southeast Asian geoscience organizations to meet and discuss the future of GEOSEA. Following an agreement to hold the next conference in Malaysia in 1984, this article highlights the development of GEOSEA from its beginning 12 years ago in Kuala Lumpur to the recent Manila meeting.

\section{The Origin of GEOSEA}

In 1970, the increasing interest in the geology of the SE Asian region, especially among the petroleum sector, encouraged the Geological Society of Malaysia (GSM) to begin planning its first regional geological conference. The purpose was to allow geoscientists working in the region to disseminate information on advances and innovations in geology and the application of new techniques in mineral and energy resource exploration. The wide response to the first GEOSEA, held in Kuala Lumpur in 1972, was a clear indication of the need for such a regional conference, not only by geoscientists in this region, but among others interested in new developments and progress in SE Asian geology.

Compared to later GEOSEA meetings, the first conference was run on a modest budget. Although support was obtained from the Malaysian government, organization and financing of the conference was left to the non-governmental GSM with the help of geology students from local universities. Financial assistance was also obtained from mining and petroleum companies and from the UNESCO Jakarta Regional Office for Science and Technology to cover the costs of staging the conference, travel and other expenses and for publication of the proceedings. The Commission for the Geological Map of the World (CGMW) held its regional Asian workshop at the first conference and has followed this procedure at subsequent meetings.

The demands of organizing the five-day conference and its field trips left little time in 1972 to examine the future of this regional conference. The SE Asian geoscience community was well represented, however, and the 250 participants present clearly felt there was a need for further regional meetings. A small group of geologists from Indonesia offered to host a second conference in Jakarta.

At the 1975 Jakarta conference, representatives of the Ikatan Ahti Geologi Indonesia, GSM and other SE Asian geoscientists invited Thailand to host a third meeting in 1978 and similarly, in 1978, the Philippines was invited to host a fourth conference in 1981. The name "GEOSEA" was introduced in 1978 for the third regional conference in Thailand. Its hammer and twinned cassiterite symbol was adopted in Manila and seems likely to remain the logo for future conferences.

Despite the conference's rather informal nature - no on-going secretariat exists, for example - GEOSEA since 1972 has developed into a well-established event organized with technical sessions, workshops, training courses, seminars, working group meetings and field trips lasting up to two weeks. Each GEOSEA has taken on its own unique character, and no "ground rules" have been set.
For example, the three-year interval between each conference has never been formally discussed and agreed upon but now appears to be accepted practice. The informal nature has even extended to the boundaries of the SE Asian region which were defined in 1972 as the region stretching from Burma on the west to Taiwan in the east and south to Papua New Guinea. This definition has remained the same for subsequent conferences, however, recent GEOSEAs have included contributions from as far distant as India, China, South Korea and Pacific Islands.

Organizations such as AGID, the UNESCO-sponsored Geoscience Network for Southeast Asia, CGMW, and CCOP have held meetings, training sessions and other information programs at one GEOSEA or another. Because all SE Asian countries, except Singapore and Hong Kong, are developing countries which rely heavily on their mineral resources for economic progress, a practical training program incorporated into the more academic-based technical sessions has been extremely worthwhile. This program will probably be given more prominence in future GEOSEAs.

The geological societies in each of the host countries have played an important role in organizing the conferences. But equally important and sometimes more prominent, have been the Geological Surveys, Bureau of Mines or National Geoscience Committees. Governmental involvement, however, has not altered in any way the non-political nature of this conference.

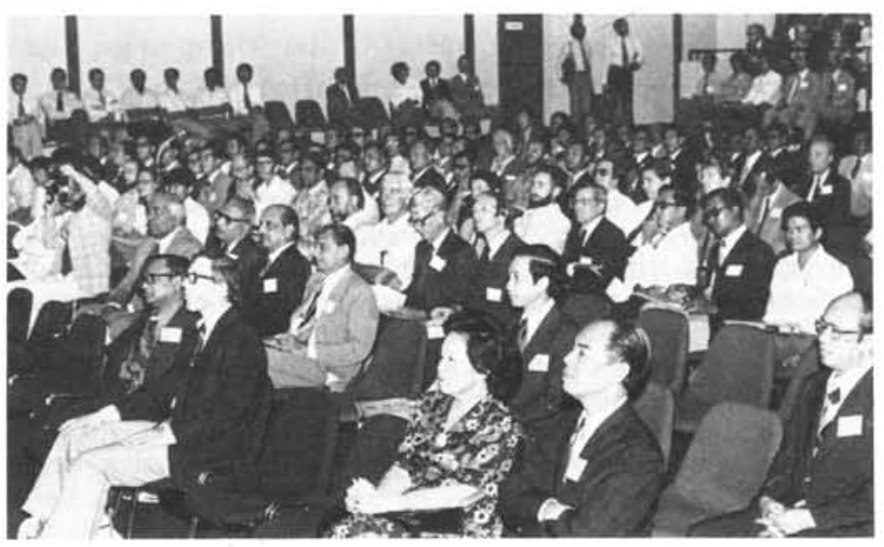

Participants at the opening ceremony of GEOSEA III, Bangkok, 1978. 
The Bangkok meeting in 1978 was unique in that, for perhaps the first time in an international geological meeting, participants from China and Taiwan, identified respectively as from Peking and Taipei, presented papers at the same meeting. The recent Manila meeting saw the return of an enthusiastic contingent from Vietnam who brought with them a specially-printed 122-page "Additional Proceedings of GEOSEA IV" with 15 papers on aspects of Vietnamese geology written in English.

\section{GEOSEA IV, Manila, November 18-20, 1981}

Nearly 400 geoscientists from more than 25 countries converged on Manila during the latter half of November, 1981. Under the direction of Mr. Juanito C. Fernandez, Director of the Philippines's Department of Mines and Geosciences, the organizers of individual sessions assembled papers covering nearly all aspects of developments in the geosciences in the region. Although much of the interest appeared to focus on tectonics and metallics, other subjects, such as geophysics, geochronology, geochemistry, coal, geothermal energy, uranium, and Quaternary geology, had their share of the audience.

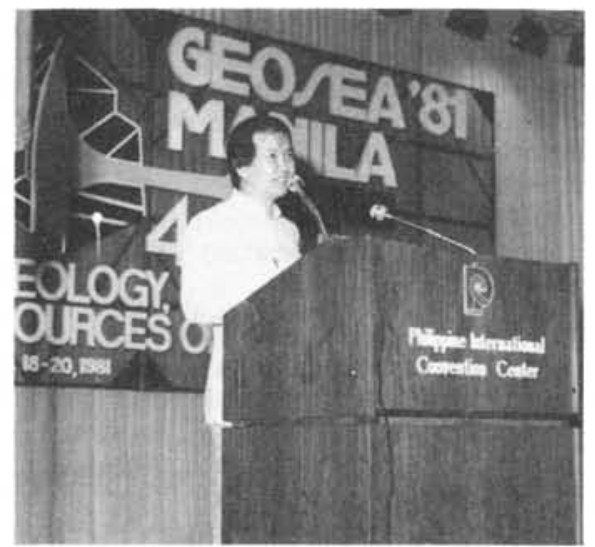

Jesus Galang opens GEOSEA IV, Manila, November 18, 1981.

A notable feature of this meeting was the active participation of a large number of young Filipino geologists who presented papers on the geology of their country. Many participants took an active part in other workshops and training courses as well as the field program, which included visits to copper, gold and chromite mines and a geothermal plant. SEATAR held a workshop on the Luzon-Marianas transect and a field trip to the Zambales district of the Philippines; CCOP ran a remote sensing course with emphasis on coastal and offshore surveys.

\section{Workshop on Geoscience Education in Asia}

On November 17, 1981, some 50 GEOSEA participants attended a one-day workshop on the role of geoscience education institutes in natural resources development in SE Asia. This was convened by Dr. Raymundo Punongbayan of the University of the Philippines and sponsored by AGID in cooperation with the Regional Network for Geoscience and the Philippine National Committee on Geological Sciences (PNCGS). The objective of the workshop was to explore ways and means of encouraging and fostering cooperation between university geoscience departments, industry and governmental organizations in the region, such activities being notably absent at present.

Any session on geoscience education is bound to set off vigorous debate, and this workshop was no exception. After an initial 10 seconds of silence, the chairman, Dr. John Lovering from the University of Melbourne, Australia, triggered off successive typhoonic waves of unabated discussion.

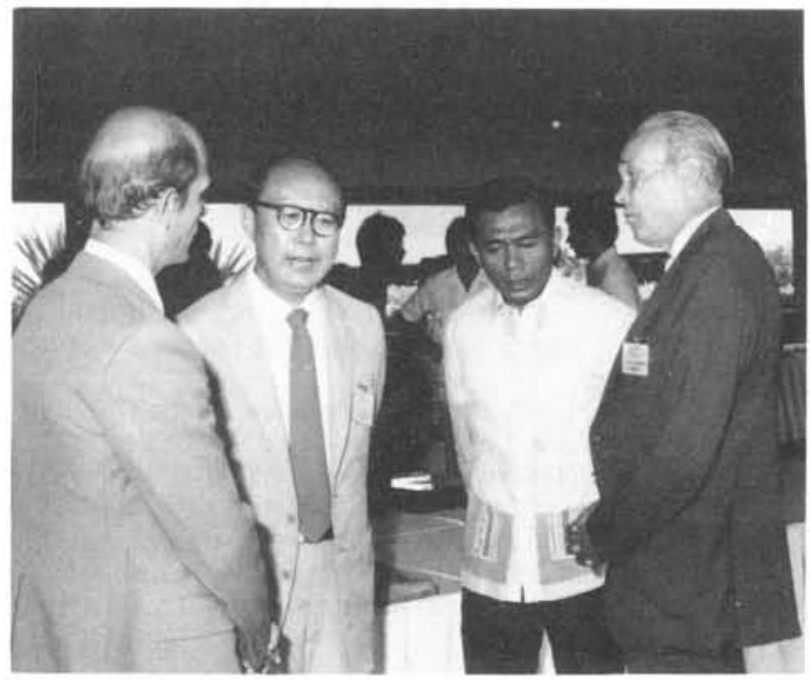

$(l-r)$ : I. Bondarenko and B. Zhang, ESCAP (Bangkok); J. Fernandez (Chairman of GEOSEA IV); and P.H. Ljunggren, RMRDC (Bandung).

Some of the points raised were familiar to those involved in geoscience education elsewhere, but they were nonetheless important for this first statement from an Asian perspective.

One participant pointed out, for example, that suspicion of the intentions of academic geologists on the part of industry was an important barrier to closer cooperation. From the university standpoint another factor was the excessive confidentiality of information acquired and held by the petroleum and mining companies. Industry spokesmen pointed out that vacation jobs for undergraduates may be readily available if the universities make the effort to seek them out. Academic geologists in turn pointed out that government and industry in SE Asia in many cases lack expertise which universities can provide. Research links between government and industry, for example, could take the form of contracts or joint research in small, key areas. Many suggestions were also made that local geoscience societies take the lead in promoting better relations between university, government and industry, and the splendid example of the GSM workshops and seminars in Malaysia, organized for this purpose, were of ten quoted.

There was also active discussion of the need for universities to keep up with the changing requirements of industry and government both in terms of manpower requirements and curriculum. Examples quoted were the shift from tin toward petroleum in Malaysia, the growing importance of geothermal energy in the Philippines, and the need for more geotechnical specialists in Hong Kong. Of course, the perennial question was also raised as to whether to aim for graduates well versed in the basics or with more specialized training. In Thailand, for example, most geologists join the government upon graduation, where they may be posted at its discretion regardless of specialized training acquired. Clearly in this case the need is for graduates strong in the basic subjects. In contrast, smaller companies in Malaysia need geologists who are able to take on specialized tasks immediately. A closer look at the design of curriculum during the workshop led to a recommendation that geoscience be introduced at the highschool level in SE Asia as part of the general science syllabus.

Though brief, this workshop sparked such interest that plans are now under way for a number of follow-up activities. These include compiling inventories of research facilities and training courses, organizing short courses for school teachers, and future education workshops in other parts of Asia. 


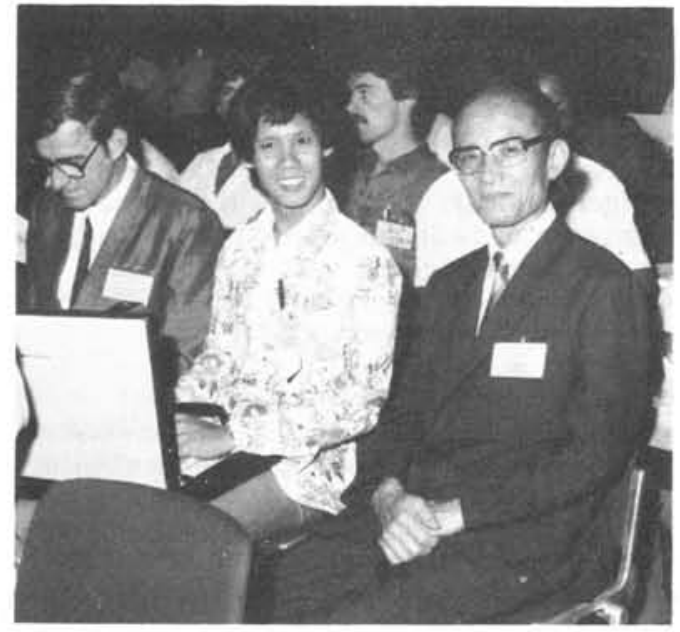

(l-r): P.H. Stauffer (Malaysia); Lee Chai Peng (Malaysia); and H. Sawata, Japan/Thailand.

\section{First Geothermal Energy Training Course}

On November 21, the Society of Energy Explorationists of the Philippines (SEEP), PNCGS and AGID organized a one-day course followed by a one-day field excursion on geothermal energy. Both events were arranged by Mr. Jesus Galang, Vice-President of the Geological Society of the Philippines and President of SEEP. Dr. Rogelio Datuin, the "father" of Philippine geothermal development, was the chairman.

This was a most appropriate topic since the Philippines have developed geothermal energy to such an extent that it now ranks No. 2 in the world with an electrical generating capacity of 446 megawatts. If current plans are realized, by 1985 the Philippines will probably lead the world in geothermal electric power generation from its 25 identified geothermal fields. Although the first experimental electricity production began in 1967, most of the big generating plants have come on stream in the past five years. The Makiling-Banahew plant, which was visited on the field trip, began generating electricity on a commercial scale less than five years after the first discovery well. In 1978, the Philippines imported oil costing some $\$ 890$ million (U.S.). It is estimated that a 55 -megawatt geothermal plant, costing about $\$ 500$ per kilowatt of installed energy capacity, can produce electricity equivalent to some \$25 million per year of imported oil at $\$ 32$ per barrel.

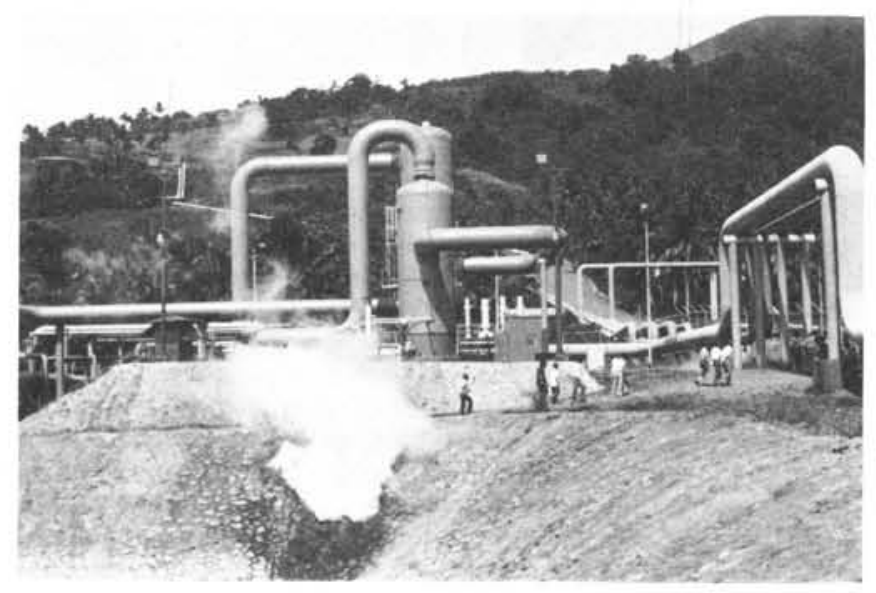

Separators for water and steam, at the 165 megawatt Makiling-Banahaw geothermal plant, Laguna, Philippines.
Interest in this course far exceeded the expectations of the organizers and the registration totalled more than 70 . The instructors were mainly experts currently engaged in geothermal energy development in the Philippines. The course presented an overview of all aspects of geothermal energy development, from geothermal legislation, exploration techniques, drilling, well testing, and power plant design, to economics of geothermal field development and environmental implications. The program was especially beneficial to other SE Asian geoscientists interested in learning more about developing the geothermal energy potential in their own country.

Much of the information and data presented at this training course was new, even for those involved in geothermal energy in the Philippines, demonstrating the invaluable role of such meetings for the exchange of information. The interest shown by geoscientists within the Philippines for such activities has resulted in similar courses being run elsewhere in the region. Indeed, plans are now being formulated for a short course for East African geothermal specialists using resource persons from the Philippines.

\section{The Future of GEOSEA}

During GEOSEA IV, a meeting of representatives of national geoscience organizations in SE Asia was convened by the Philippines, the host country, to discuss the future of these regional conferences.

The concept of GEOSEA received overwhelming support, and the geoscience organizations in this region agreed on the importance of continuing this triennial meeting. Defining the boundaries of SE Asia continued to present some difficulties but for practical purposes the definition proposed at the 1972 Kuala Lumpur meeting will be used to represent the core of the SE Asian region. Neighbouring countries will constitute the periphery zone; contributions from these countries relating to the geology of the core area or of particular interest to the core region may be included.

The need for a GEOSEA Secretariat and a charter was also discussed. Malaysia, as the next host, was given the task of drawing up guidelines to be presented at GEOSEA V. There was general agreement that a meeting of regional geoscience organizations will become a regular feature of the program. The meeting also agreed on a list of "points of contact" for each country in the region and the host country was delegated to communicate with these contact people or groups on a regular basis. Financing of meetings will be left to the host country and it was unanimously agreed to maintain the nonpolitical nature of the conference.

Most participants felt that the benefits of GEOSEA conferences extended beyond the aims of providing a forum for exchange of geological information and discussion on SE Asian geology and mineral resources. The willingness of SE Asian organizations to take on the task of staging such conferences without any official backing or financial guarantees clearly shows the goodwill and cooperation that exists within the geoscience community. Many SE Asian geoscientists are excluded from current research projects, workshops and training courses which are conducted at governmental levels and the GEOSEA program offers a rare opportunity for geoscientists from different sectors to discuss their common problems. Only a few geoscientists from this region are known internationally; many geological papers appearing in international journals give an impression that little, if any, geological information is available from within the region.

The publication of the GEOSEA proceedings will help to draw attention to the extensive geological research and mapping that has been carried out by geoscientists within the region, 


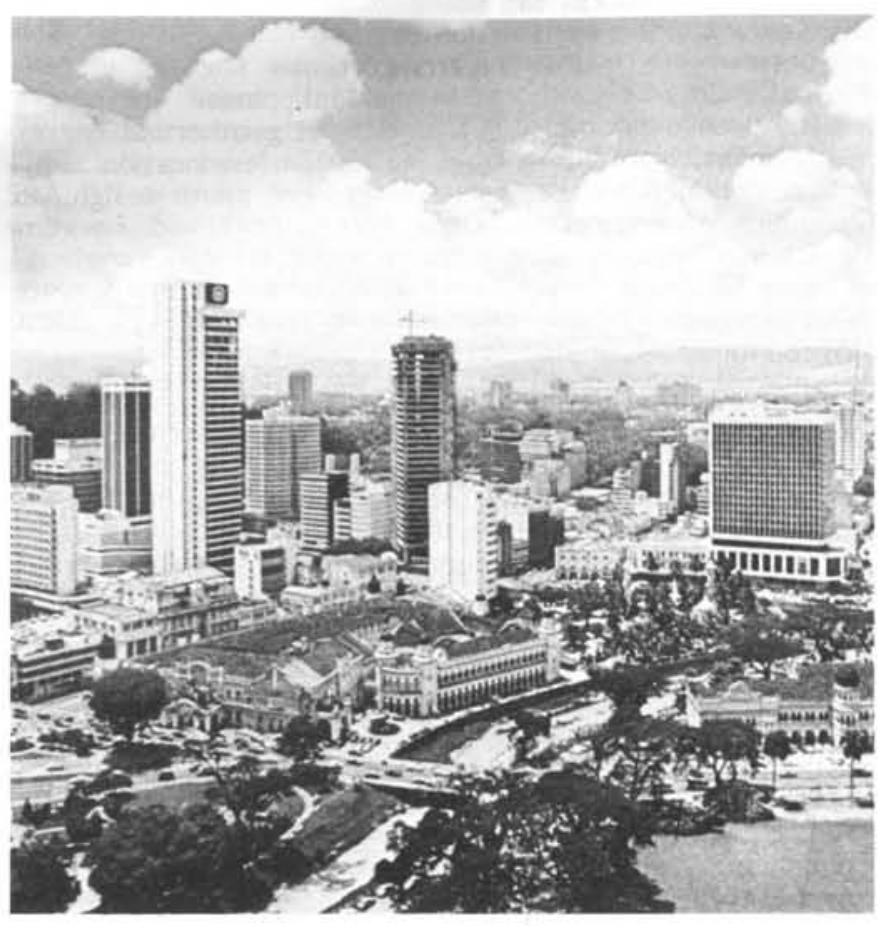

Kuala Lumpur - venue for GEOSEA V - 1984

available either in reports or other publications within each country, sometimes in their national languages. Each of the four host countries for GEOSEA programs have witnessed a marked strengthening of their local geoscience organization following the experience of organizing such a major undertaking.

Despite the advances made over the past nine years, it is clear that some problems have still to be overcome before this GEOSEA program can be said to be as firmly established as the International Geological Congress (IGC). Financing is likely to remain a major problem. A high registration fee to cover the costs may be acceptable to geoscientists sponsored by their own organizations or from industrialized countries, but will deter many participants from developing countries. A secure core funding for publication and other administrative costs is essential and SE Asian geoscience organizations will have to continue to explore various avenues, including international aid agencies in neighbouring countries with an interest in the SE Asian region, such as Japan and Australia.

\section{Possible Union of Southeast Asian Geological Sciences}

During GEOSEA IV, a suggestion was made to form a Union of Southeast Asian Geological Sciences, an organization which would provide assistance to promote GEOSEA conferences and cater to other regional programs between each GEOSEA. A clear parallel was drawn between the SE Asian situation and that of the IGC of which IUGS is the direct descendant. It is forseeable that GEOSEA with its wellestablished links between geological organizations in SE Asian countries could lead to the establishment of a SE Asian union similar to IUGS. The aims would be similar: to promote and encourage the study of geological problems in the SE Asian region; to facilitate regional cooperation in geology and related sciences; to provide continuity in regional cooperation in geology; and to assist and promote the staging of GEOSEA conferences.
Geoscientists and geoscience organizations in the SE Asian region appear to be ready to take on the task of promoting geoscience activities related to the needs of this region. Moral and financial support from established organizations such as UNESCO or IUGS could speed up the process of creating a Union of Southeast Asian Geological Sciences. It was interesting to note that UNESCO was instrumental in persuading geoscientists to agree to the formation of IUGS with an assurance of financial support. It was suggested that UNESCO's SE Asian regional office would also benefit by having a union to deal with geoscientific disciplines through a formal and convenient channel.

\section{GEOSEA $V$}

GEOSEA V will be held in early 1984 in Malaysia, and correspondence may be addressed to the Geological Society of Malaysia, c/o Department of Geology, University of Malaya, Kuala Lumpur, Malaysia.

\section{ABOUT THE AUTHORS:}

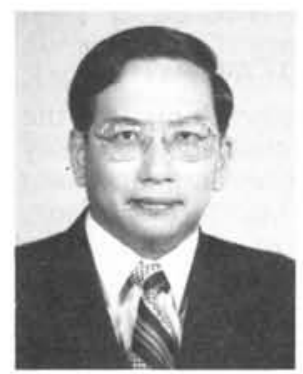

Dr. Tan Bock Kang was recently appointed Head of the Department of Geology at the University of Malaya in Kuala Lumpur. A structural geologist with an interest in engineering geology, he is a former President of the Geological Society of Malaysia, current Secretary-General of AGID, and the convener of the 1st GEOSEA Conference in 1972.

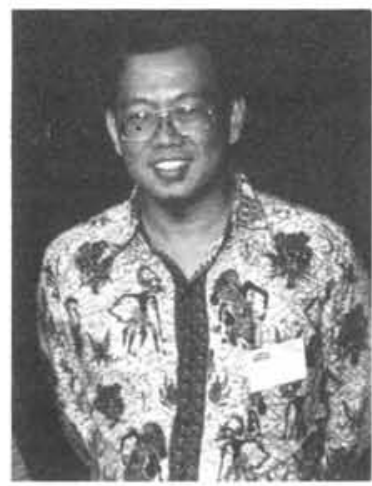

Dr. Khoo Teng Teong also teaches in the Department of Geology of the University of Malaya, with special interests in metamorphic petrology and mineralogy. He is President of the Geological Society of Malaya, Treasurer of AGID, Chairman of the Organizing Committee for the next GEOSEA conference to be held in 1984, and a noted durian fancier. 